\title{
Response of Rainfed Wheat Genotypes to Drought Stress Using Drought Tolerance Indices
}

\author{
Reza Drikvand ${ }^{1}$, Behrooz Doosty ${ }^{1} \&$ Tahmaseb Hosseinpour ${ }^{2}$ \\ ${ }^{1}$ Department of Agronomy and Plant Breeding, Khorramabad branch, Islamic Azad University, Iran \\ ${ }^{2}$ Lorestan Agriculture and Natural Resources Center, Khorramabad, Iran \\ Correspondence: Reza Drikvand, Department of Agronomy and Plant Breeding, Khorramabad branch, Islamic \\ Azad University, Khorramabad, Iran. Tel: 98-661-422-6470. E-mail: drikvand_f@yahoo.com
}

$\begin{array}{lr}\text { Received: March 16, } 2012 & \text { Accepted: April 9, } 2012 \quad \text { Online Published: May 22, } 2012 \\ \text { doi:10.5539/jas.v4n7p126 } & \text { URL: http://dx.doi.org/10.5539/jas.v4n7p126 }\end{array}$

The research is financed by Deputy of Research and Technology of Islamic Azad University, Khorramabad Branch, Iran.

\begin{abstract}
Ten wheat genotypes were tested in a randomized complete block design with three replications under two irrigated and rainfed conditions to identify drought tolerant genotypes. Indices of drought tolerance were calculated based on the potential $\left(\mathrm{Y}_{\mathrm{p}}\right)$ and under stress $\left(\mathrm{Y}_{\mathrm{s}}\right)$ yield. Analysis of variance of indices exhibited highly significant differences among the geometric mean productivity (GMP), mean productivity (MP) and stress tolerance index (STI) and non-significant differences between the stress susceptibility index (SSI) and stress tolerance (TOL) indices. This indicates the existence of genetic variation for the attributes studied and the possibility of selection for drought tolerance genotypes. The highest significant positive correlations were found among GMP, MP and STI indices and potential and under rainfed yield. The highest GMP, MP, and STI were related to the TV2 genotypes. Principal component analysis reduced five indices down to two components with $99.49 \%$ proportional cumulative variance. Correlation and principal component analysis indicated that the most suitable criteria for the identification of genotypes under irrigated and rainfed conditions were GMP, MP and STI indices. Three dimensional plots exhibited that TV2 was the best drought tolerance genotype. Results of biplot analysis also identified the same genotype as the highest yielding one in both conditions.
\end{abstract}

Keywords: rainfed wheat, drought stress, principal component, tolerance indices

\section{Introduction}

Wheat is an important crop in Iran most of this crop is grown under varied rainfed and water stress conditions. Several selection criteria have been proposed for selecting genotypes based on their performance in stress and non-stress environments (Fischer \& Maurere 1978; Rosielle \& Hamblin 1981; Frnandez 1992). Drought indices which provide a measure of drought based on loss of yield under drought conditions in comparison to normal conditions have been used for screening drought tolerant genotypes (Mitra, 2001). Rosielle and Hamblin (1981) defined stress tolerance (TOL) as the differences in yield between the stress (Ys) and non-stress environments (Yp) and mean productivity (MP) as the average yield of Ys and Yp. Fischer and Maurere (1978) proposed a stress susceptibility index (SSI). Fernandez (1992) defined geometric mean productivity (GMP) and stress tolerance index (STI). STI index can be used to identify genotypes that produce high yield under both stress and non-stress conditions. Sio se mardeh et al. (2006) used drought tolerant indices in wheat and found that under moderate stress, MP, GMP and STI were more effective in identifying high yielding cultivars in both drought-stressed and irrigated conditions, under severe stress, none of the indices used were able to identify group high yielding cultivars. Clarke et al. (1992) used SSI for evaluation of drought tolerance in wheat genotypes and found a year-to-year variation in SSI for genotypes and their ranking pattern. Guttieri et al. (2001) using SSI criterion suggested that SSI more than one indicating above-average susceptibility and SSI less than one indicated the below-average susceptibility to drought stress. Fernandez (1992) proposed STI index for identifying mungbean genotypes with high yield and stress tolerant potentials. The main objectives of this study were to identify the high yielding and drought tolerant genotypes and to introduce them for the cultivation in rainfed areas in Lorestan province of Iran. 


\section{Materials and Methods}

\subsection{Expremental Design and Plant Material}

The experiment was conducted at Research farm of Lorestan Agricultural and Natural Resources Research Center, located at Khoramabad, Iran (5 km west of Khoramabad, Latitude $33^{\circ} 20^{\prime}$, longitude $48^{\circ} 20^{\prime}$, altitude $1200 \mathrm{~m}$ ) during growing seasons of 2010-2011. The experimental material consisted of 10 rainfed wheat genotypes (Table 1) were evaluated using a randomized complete block design with three replications each of them under irrigated and rainfed conditions. Each plot contained 4 rows with $20 \mathrm{~cm}$ apart and $6 \mathrm{~m}$ in length. This study consisted of two separate experiments and plants were evaluated for grain yield.

Table 1. Rainfed wheat genotypes in the experiment

\begin{tabular}{ccc}
\hline No & Genotype & Growth type \\
\hline 1 & Azar2 & winter \\
2 & Sardari & winter \\
3 & Kohdasht & spring \\
4 & Shahivandi & spring \\
5 & Symareh & spring \\
6 & Zagros & spring \\
7 & Gahar & spring \\
8 & Maroon & spring \\
9 & Irena & spring \\
10 & TV2 & spring \\
\hline
\end{tabular}

\subsection{Calculate Indices}

Five selection indices of drought tolerance including stress susceptibility index (SSI), stress tolerance index (STI), tolerance (TOL), mean productivity (MP) and geometric mean productivity (GMP) were calculated based on the yield under two environments. Stress tolerance attributes were calculated by the following formula (Fischer \& Maurer, 1978; Rosielle \& Hambelen, 1981; Fernandez, 1992).

$$
\mathrm{SSI}=[1-(\mathrm{Ys}) /(\underline{\mathrm{Yp}})] / \underline{\mathrm{SI}}))]
$$

Where $\mathrm{SI}$ is the stress intensity and calculated as: $\mathrm{SI}=[1-(\overline{Y S}) /(\overline{Y p})]$.

$$
\begin{gathered}
\mathrm{TOL}=(\mathrm{Yp}-\mathrm{Ys}) \\
\mathrm{MP}=(\mathrm{Yp}+\mathrm{Ys}) / 2 \\
\mathrm{STI}=\left[(\mathrm{Yp}) \times(\mathrm{Ys}) /(\overline{Y p})^{2}\right] \\
\mathrm{GMP}=\sqrt{(Y s \times Y p)}
\end{gathered}
$$

Where Ys and Yp are the yields of genotypes evaluated under irrigation and rainfed conditions and $\overline{Y s}$ and $\overline{Y p}$ are the mean yields over all genotypes evaluated under stress and non-stress conditions. To display the genotype by trait two way data in biplot, a principal component analysis is necessary. The principal components the original data set, consisting of $n$ measurements on $p$ variables, are reduced to one consisting of $n$ measurements on $k$ principal components. The biplot display of principal component analysis was used to identify suitable stress tolerant indices, stress tolerant and high-yielding genotypes. Analysis of principal components often reveals relationships that were not previously suspected and thereby allows interpretations that would not ordinarily result (Johanson \& Wichern, 1996). Genotypes can be categorized into four groups based on their performance in stress and non stress environments: genotypes express uniform superiority in both stress and non stress environments (Group A), genotypes perform favorably only in non stress environments (Group B), genotype gives relatively higher yield only in stress environments (Group C), and genotypes perform poorly in both stress and non stress environments (Group D). The optimal selection criterion should distinguish Group A from the other three groups. Three-dimensional plots among $\mathrm{Y}_{\mathrm{S}}$ (x-axis), Yp (y-axis) and STI (z-axis) showed the interrelationships among these three variables to separate genotypes of Group A from other groups (Fernandez, 1992). 


\subsection{Statistical Analysis}

Analysis of variance, correlation among traits, correlation among indices and grain yield in two environments, three-dimensional plots drawing, principal component analysis and biplot drawing were performed using SAS (SAS Institute 2002), SPSS (version 11.5) and Stat Graphic (version 2.1) software, respectively.

\section{Results and Discussion}

\subsection{Analysis of Variance}

Analysis of variance of grain yield under irrigation and rainfed conditions showed significant differences for grain yield performance and all the indices except SSI and TOL indices (Table 2). It indicated that genetic variation exists among genotypes. Mean comparison of grain yield and indices were carried out using Duncan's multiple rang test and showed in Table 3. The genotypes Maroon, Ghahar and Irena in the irrigated condition and genotypes Symareh and TV2 in rainfed condition had the highest performance. The genotype symareh had less grain yield fluctuation and Sardari genotype had high grain yield fluctuation in two conditions. According to indices, the highest GMP, MP, STI were related to the genotype TV2.

Table 2. Anova of drought tolerance indices, under irrigated and rainfed grain yield in wheat genotypes

\begin{tabular}{lcccccccc}
\hline \multicolumn{8}{c}{ MS } \\
\hline S.O.V & df & $\mathrm{Y}_{\mathrm{p}}$ & $\mathrm{Y}_{\mathrm{s}}$ & GMP & MP & SSI & STI & TOL \\
\hline Replication & 2 & 4292871 & 130078.12 & 967783.95 & 1273423.94 & 0.70 & 0.01 & 3429753.90 \\
Genotype & 9 & $890639^{*}$ & $522337.96^{*}$ & $518092.54^{* *}$ & $486320.50^{* *}$ & $0.23^{\mathrm{ns}}$ & $0.04^{*}$ & $801683.44^{\mathrm{ns}}$ \\
Error & 18 & 323180.70 & 146643.51 & 96507.39 & 124918.25 & 0.12 & 0.01 & 449518.08 \\
\hline
\end{tabular}

ns, ${ }^{*}$, and ** : Not significant, significant at $5 \%$ and $1 \%$ levels of probability, respectively

Table 3. Mean comparison of drought tolerance indices, under irrigated and rainfed yield in wheat genotypes using Duncan's method

\begin{tabular}{clccccccc}
\hline No & Genotype & Yp $(\mathrm{kg} / \mathrm{hac})$ & Ys(kg/hac) & GMP & MP & SSI & STI & TOL \\
\hline 1 & Sardari & $4520.8 \mathrm{c}$ & $2968.8 \mathrm{~d}$ & $3648.2 \mathrm{c}$ & $3744.8 \mathrm{~d}$ & $1.08 \mathrm{abc}$ & $0.49 \mathrm{~d}$ & $1552.1 \mathrm{ab}$ \\
2 & Azar2 & $4562.5 \mathrm{c}$ & $3208.3 \mathrm{~cd}$ & $3678.8 \mathrm{c}$ & $3885.4 \mathrm{~cd}$ & $0.96 \mathrm{abc}$ & $0.54 \mathrm{~cd}$ & $1354.2 \mathrm{ab}$ \\
3 & Kohdasht & $4656.3 \mathrm{c}$ & $3791.7 \mathrm{abc}$ & $4172.6 \mathrm{abc}$ & $4224 \mathrm{abcd}$ & $0.53 \mathrm{bc}$ & $0.64 \mathrm{abcd}$ & $864.6 \mathrm{~b}$ \\
4 & Shahivandi & $4697.9 \mathrm{bc}$ & $3322.9 \mathrm{~cd}$ & $3946.7 \mathrm{bc}$ & $4012.1 \mathrm{bcd}$ & $0.83 \mathrm{abc}$ & $0.57 \mathrm{bcd}$ & $1357 \mathrm{ab}$ \\
5 & Symareh & $5145.8 \mathrm{abc}$ & $4354.2 \mathrm{a}$ & $4723.4 \mathrm{a}$ & $4750 \mathrm{a}$ & $0.46 \mathrm{c}$ & $0.79 \mathrm{ab}$ & $825 \mathrm{~b}$ \\
6 & Zagros & $5437.5 \mathrm{abc}$ & $3489.6 \mathrm{bcd}$ & $4296.8 \mathrm{ab}$ & $4463.5 \mathrm{abc}$ & $1.15 \mathrm{abc}$ & $0.69 \mathrm{abcd}$ & $1947.9 \mathrm{ab}$ \\
7 & Gahar & $5760.4 \mathrm{ab}$ & $3718.8 \mathrm{abc}$ & $4629.3 \mathrm{a}$ & $4739.6 \mathrm{a}$ & $1.14 \mathrm{abc}$ & $0.79 \mathrm{ab}$ & $2041.7 \mathrm{ab}$ \\
8 & Maroon & $5875 \mathrm{a}$ & $3614.6 \mathrm{bcd}$ & $4583.9 \mathrm{a}$ & $4744.8 \mathrm{a}$ & $1.19 \mathrm{ab}$ & $0.77 \mathrm{abc}$ & $2260.4 \mathrm{a}$ \\
9 & Irena & $5781.3 \mathrm{ab}$ & $3458.3 \mathrm{bcd}$ & $4456.7 \mathrm{ab}$ & $4619.8 \mathrm{ab}$ & $1.26 \mathrm{a}$ & $0.70 \mathrm{abcd}$ & $2189.6 \mathrm{a}$ \\
10 & TV2 & $5500 \mathrm{abc}$ & $4135.4 \mathrm{ab}$ & $4759.1 \mathrm{a}$ & $4817.6 \mathrm{a}$ & $0.74 \mathrm{abc}$ & $0.85 \mathrm{a}$ & $1364.6 \mathrm{ab}$ \\
\hline
\end{tabular}

Means followed by same letters in each column are not significantly at $5 \%$ levels of probability

\subsection{Correlation Analysis}

Correlation analysis among grain yield under two environments and drought tolerant indices were performed. GMP, MP and STI indices that were correlated with grain yield under two conditions (Table 4) are suitable indices for screening wheat genotypes. These findings are in accordance with the results of Golabadi et al. (2006) in durum wheat. The observed relationship between Yp and MP - STI and Ys and MP - STI are in consistent with those reported by Fernandez (1992) in mungbean and Farshadfar and Sutka (2003) in maize. Ramirez and Kelly (1998) observed positive and significant correlation of some yield components with GMP in common bean. Nasir ud-Din et al. (1992) showed significant and positive correlation between Ys and TOL, and Ys and MP as well as between Yp and MP, while TOL was negatively correlated with Yp and MP. 
Table 4. Simple correlation coefficients matrix between drought tolerance indices, under irrigated and rainfed grain yield

\begin{tabular}{llllllll}
\hline & 1 & 2 & 3 & 4 & 5 & 6 & 7 \\
\hline 1-Yp & 1 & & & & & & \\
2-Ys & $0.39^{\mathrm{ns}}$ & 1 & & & & & \\
3-GMP & $0.81^{* *}$ & $0.84^{* *}$ & 1 & & & & \\
4-MP & $0.87^{* *}$ & $0.79^{* *}$ & $0.99^{* *}$ & 1 & & & \\
5-SSI & $0.47^{\mathrm{ns}}$ & $-0.61^{\mathrm{ns}}$ & $-0.11^{\mathrm{ns}}$ & $-0.01^{\mathrm{ns}}$ & 1 & & \\
6-STI & $0.80^{* *}$ & $0.84^{* *}$ & $0.98^{* *}$ & $0.98^{* *}$ & $-0.11^{\mathrm{ns}}$ & 1 & \\
7-TOL & $0.95^{* *}$ & $0.39^{\mathrm{ns}}$ & $0.81^{* *}$ & $0.87^{* *}$ & $0.47^{\mathrm{ns}}$ & $0.80^{* *}$ & 1 \\
\hline
\end{tabular}

ns, *, and ** : Not significant, significant at $5 \%$ and $1 \%$ levels of probability, respectively

\subsection{Principal Component Analysis}

In order to further investigation on relationship among genotypes and drought tolerance indices, principal component analysis were performed (Table 5) that was reduced five indices down two components. PCA revealed that the first component explained $73 \%$ of the variation with Yp, Ys, MP, GMP and STI. Thus, the first dimension can be named as the yield potential and drought tolerance. Considering the positive value of this PCA on biplot, selected genotypes will be high yielding under rainfed and irrigated conditions. The second PCA explained $26.49 \%$ of the total variation and had the positive correlation with Ys and TOL. Thus selection of genotypes that have high PCA1 and low PCA2 are suitable for rainfed and irrigated environments. Golabadi et al. (2006) and Farshadfar and sutka (2003) obtained similar results in F3 and F4 families of durum wheat, and in wheat substitution lines, respectively. Furthermore this result confirms results of investigation of Normand Moayyed et al. (2001) in wheat and Zabet et al. (2003) in mungbean. The relationship between the genotypes and drought tolerant indices can be plotted in same graph (the biplot). The biplot provides a useful tool for data analysis. The angles and directions between the attribute vectors illustrate the strength and the direction of correlation between any two attributes (Fernandez, 1992). In the present study, significant positive correlations between STI, GMP and STI, MP and STI, $Y_{S}$ and STI, $Y_{P}$ were revealed in biplot (Figure 1). Drawing biplot using relationships among above indices indicated that the most suitable criteria for the identification of genotypes under irrigated and rainfed conditions were GMP, MP and STI indices. The results obtained from biplot graph confirmed correlation analysis. These results are in agreement with the findings of Fernandez (1992), Farshadfar (2000) and Golabadi et al. (2006). Considering the biplot genotypes with larger component_1 and lower component 2, scores gave high yields (stable genotypes), and genotypes with lower component_1 and larger component_2 scores had low yields (unstable genotypes). Therefore in this study TV2 and Symareh genotypes had stable grain yield, Azar2 and Sardari genotypes had unstable grain yield under irrigated and rainfed conditions (genotypes numbers: 10, 5 and 1, 2 , respectively). Since the experiment was conducted in moderate temperature climates and considering Azar2 and Sardari genotypes are suitable for planting in the cold areas, so these genotypes had low grain yield.

Table 5. The principal component analysis for drought tolerance indices

\begin{tabular}{cccccccccc}
\hline Component & Eigen value & Cumulative percentage & Ys & Yp & GMP & MP & SSI & STI & TOL \\
\hline 1 & 5.11 & 73 & 0.39 & 0.33 & 0.43 & 0.44 & 0.01 & 0.43 & 0.30 \\
2 & 1.85 & 26.49 & 0.32 & -0.47 & -0.10 & -0.010 & 0.73 & -0.11 & 0.32 \\
\hline
\end{tabular}

Biplot

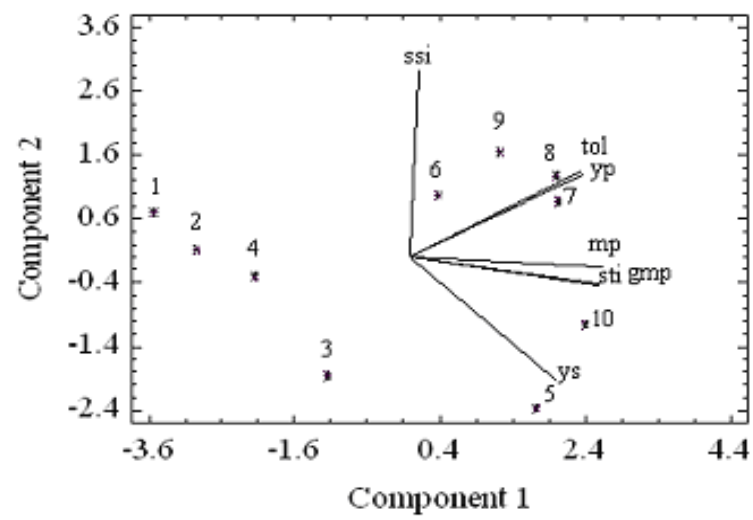

Figure 1. The biplot of 10 rainfed wheat genotypes and 5 indices based on 1 and 2 component 


\subsection{Three Dimensional Plots}

In order to identify drought tolerant genotypes, three dimensional plots were drawn (Figure 2 and 3). In three-dimensional plots the X-Y plane is divided into four groups and marked as group A to group D. These plots can be used effectively to distinguish the high-yielding genotypes under two environments, three-dimensional plots (Ys, Yp and STI, GMP) are presented to show the interrelationships among these three variables to separate the Genotypes of group A (high yielding genotypes in both rainfed and irrigated conditions) from the other groups (B, C and D), and to illustrate the advantage of STI and GMP indices as selection criterion for identifying high-yielding and stress tolerant genotypes. In three dimensional plots, Kohdasht and Symareh (No: 3, 5) were in $\mathrm{C}$ group. These two genotypes had high yield only in rainfed environment. The genotypes Zagros, Gahar, Maroon and Irena (No: 6, 7, 8,9) were in B group and performed favorably only in non stress (irrigation) environment. Azar2, Sardari and Shahivandi (No: 1, 2, 4) were in D group that performed poorly in both environments. The genotype TV2 (No: 10) was included in the A group (Fig. 2 and 3), this genotype had stable grain yield in two environments.

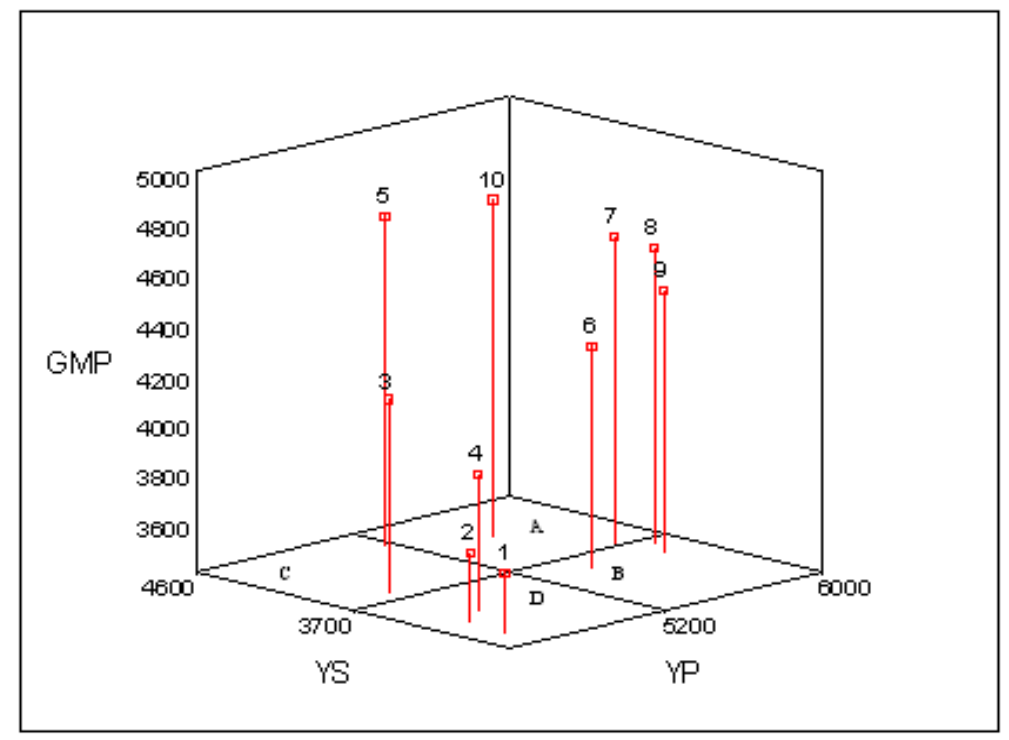

Figure 2. The 3-D plots among GMP, $\mathrm{Y}_{\mathrm{p}}, \mathrm{Y}_{\mathrm{s}}$

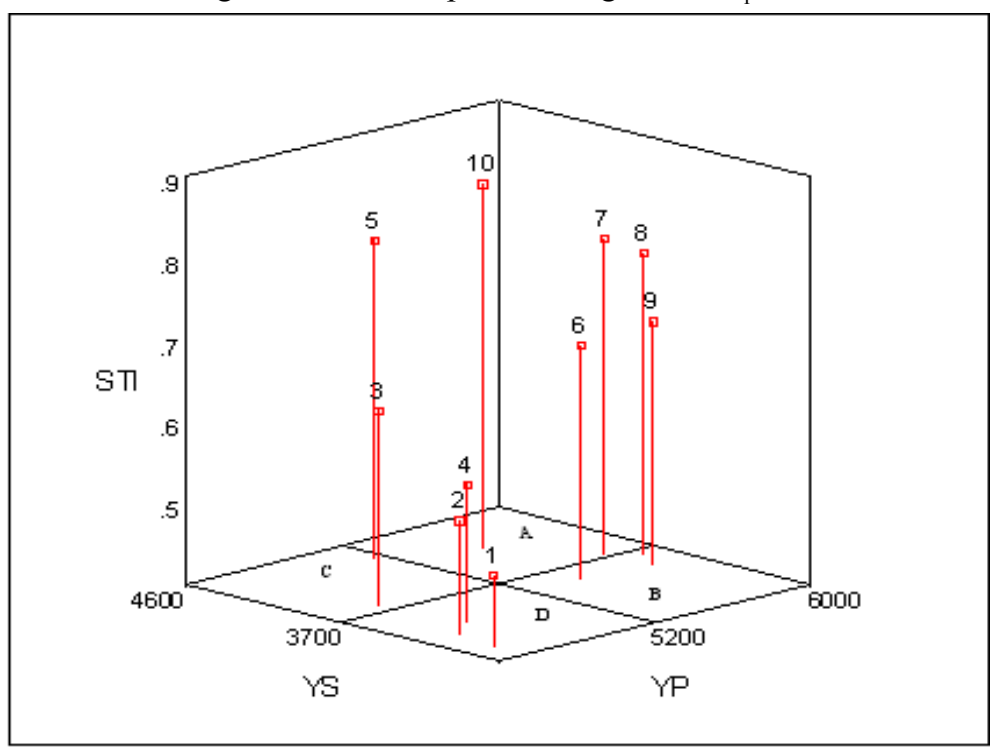

Figure 3. The 3D plots among STI, $\mathrm{Y}_{\mathrm{p}}, \mathrm{Y}_{\mathrm{s}}$

Note: In three Figures each genotype is represented by numbers (According to Table No. 1)

\section{Conclusion}

When breeder is looking for the genotype adapted for a wide range of environments, selection should be based on drought tolerant indices calculated from the grain yield under both conditions. In the present study, it was found 
that statistical methods including correlation between grain yield and indices, biplot analysis, were identified the same genotypes as tolerant. The three dimensional plot was followed the same pattern. So these statistical methods are useful for identifying drought tolerant wheat genotypes. The findings of this study, MP, GMP and STI are suggested for identifying drought tolerant genotypes and the genotype TV2 can be recommended for cultivation in rainfed areas of Lorestan province of Iran.

\section{Acknowledgments}

We would like to thank A. Mirazadi for his helpful comments and recommendations on the manuscript. The authors express their gratitude to Lorestan Agricultural and Natural Resources Research Center for preparing the grains of wheat genotypes used in the experiments.

\section{References}

Clarke, J. M., DePauw, R. M., \& Townley-Smith, T. F. (1992). Evaluation of methods for quantification of $\begin{array}{llllll}\text { drought tolerance } \quad \text { in } & \text { Crop }\end{array}$ http://dx.doi.org/10.2135/cropsci1992.0011183X003200030029x

Farshadfar, E. (2000). Selection for drought resistance in bread wheat lines. Science and Agriculture Industry, 14, 161-171. http://www.magiran.com/magarchive.asp

Farshadfar, E., \& Sutka, J. (2002). Multivariate analysis of drought tolerance in wheat substitution lines. Cereal Research Communication, 31, 33-39. http://www.akademiai.com/content/120427

Fernandez, G. C. J. (1992). Effective selection criteria for assessing plant stress tolerance. In: Proceedings of the International Symposium on Adaptation of Vegetables and other Food Crops in Temperature and Water Stress, Chapter 25, Taiwan, 13-16 August, p. 257-270.

Fischer, R. A., \& Maurer, R. (1978). Drought resistance in spring wheat cultivars. I. Grain yield responses. Australian Journal of Agricultural Research, 29, 897-912. http://dx.doi.org/10.1071/AR9780897

Golabadi, M. A., Arzani, S. A., \& Maibody, M. (2006). Assessment of drought tolerance in segregating populations in durum wheat. African Journal of Agricultural Research, 1(5), 62-171. http://www.academicjournals.org

Guttieri, M. J., Stark, J. C., Brien, K., \& Souza, E. (2001). Relative sensitivity of spring wheat grain yield and quality parameters to moisture deficit. Crop Sci., 41, 327-335. http://dx.doi.org/10.2135/cropsci2001.412327x

Johanson, R. A., \& Wichern, D. W. (1996). Applied multivariate statistical analysis, Prentice Hall of India, New Delhi, p 642

Mitra, J. (2001). Genetics and genetic improvement of drought resistance in crop plants. Current Sci., 80, 758-762. http://www.ias.ac.in/j_archive/currsci/volindex.html

Nasir Ud-Din., Carver, B. F., \& Clutter, A. C. (1992). Genetic analysis and selection for wheat yield in drought stressed and irrigated environments. Euphytica, 62, 89-96. http://dx.doi.org/10.1007/BF00037933

Normand Moayyed, F., Rostami, M. A., \& Ghannadha, M. R. (2001). Evaluation of drought resistance indices in bread wheat. Iranian Journal of Agricultural Science, 32, 795-805. http://www.sid.ir/fa/JournalList.asp?ID=1151\&Name

Ramirez, P., \& Kelly, J. D. (1998). Traits related to drought resistance in common bean. Euphytica, 99, 127-136. http://dx.doi.org/10.1023/A:1018353200015

Rosielle, A. A., \& Hamblin, J. (1981). Theoretical aspects of selection for yield in stress and non-stress environments. Crop Sci., 21, 943-946. http://dx.doi.org/10.2135/cropsci1981.0011183X002100060033x

SAS Institute. (2002). SAS user's guide: Statistics version 9 for windows. SAS Institute., Carry, NC.

Sio-Se Mardeh, A., Ahmadi, A., Postini, K., \& Mohammadi, V. (2006). Evaluation of drought resistance indices under various environmental conditions. Field Crop Research, 98, 222-229. http://dx.doi.org/10.1016/j.fcr.2006.02.001

Zabet, M., Hosseinzadeh, A. H., Ahmadi, A., \& Khialparast, F. (2003). Effect of water stress on different traits and determination of the best water stress index in Mung Bean (vigna radiate). Iranian Journal of Agricultural Science, 34, 889-898. http://www.sid.ir/fa/JournalList.asp?ID=1151\&Name 